\title{
Design of Breakdown and Checklist for Continuous Renal Replacement Therapy
}

\author{
Shujuan Wang, Yan Kang, Xiaoqing Wang (D, Lanling Wei, Yanan Zhu, and Huilin Yuan
}

Qingdao Municipal Hospital Emergency Department, Qingdao Municipal Hospital, Qingdao 266011, China

Correspondence should be addressed to Xiaoqing Wang; led2913@163.com

Received 26 October 2021; Accepted 22 November 2021; Published 1 December 2021

Academic Editor: M Pallikonda Rajasekaran

Copyright ( 92021 Shujuan Wang et al. This is an open access article distributed under the Creative Commons Attribution License, which permits unrestricted use, distribution, and reproduction in any medium, provided the original work is properly cited.

Objective. This study aimed to improve the quality of continuous renal replacement therapy (CRRT). Methods. A pool of candidate indicators was established using literature retrieval, panel discussion, and experience summary. The first round of consultation was performed with the selected 18 experts by the Delphi method. Then, the checklist was modified according to the experts' opinions for the second round of consultation to prepare the final checklist. Results. The positivity coefficients of experts in the two rounds of consultation were $100 \%$ and $88.9 \%$, respectively, with the authority coefficient of 0.88 . The Kendall coordination coefficients of the primary and secondary indicators were 0.296 and 0.303 , respectively $(P<0.05)$. Finally, the breakdown and checklist were prepared, which involved 16 primary indicators and 56 secondary indicators. Conclusion. The scientific and reasonable breakdown and checklist prepared based on a consultation can provide scientific guidance for nursing during CRRT, reduce the incidence of adverse events, and improve work efficiency and satisfaction of medical care.

\section{Introduction}

Continuous renal replacement therapy (CRRT), a continuous therapy for blood purification for around 24 hours a day to replace the damaged kidney, is the general term for continuously and slowly removing water and solutes [1]. Given the promising therapeutic effect and prognosis of CRRT, it has been widely used to treat critically ill patients. However, the multiple treatment modes have complicated the preparation and operation, bringing difficulties to homogeneous management in clinical work [2, 3]. In 2010, a total of 2.618 million people received renal replacement therapy (RRT) worldwide. It is estimated that by 2030, the number of people using RRT will be more than double to 5.439 million, with the highest growth rate in Asia (by 968,000 increased to 2.162 million) [4]. CRRT is the main approach for patients to maintain life, which can prolong the survival time and improve the quality of life. Meanwhile, CRRT has the characteristics of high technical content, substantial expertise, and high risk. Therefore, actively exploring intervention methods to improve the quality of CRRT care and developing a scientific and reasonable management plan are of practical significance to prolong the survival period of hemodialysis patients and improve the quality of life of patients. Therefore, we prepared the Breakdown and Checklist for CRRT to better cooperate with clinical work, improve the work efficiency, realize homogeneous management, and reduce the incidence of adverse events [5]. Their clinical application has obtained promising therapeutic effects, which are reported as follows.

\section{Research Methods}

2.1. Preliminary Design. A CRRT team was established to select the relevant literature articles about CRRT checklist from Chinese and English databases according to the research objectives and prepare an item pool for the breakdown and checklist according to the high-risk steps during operation and in combination with the clinical experience based on the adverse events of CRRT [6-9]. Four experts (two directors and associate chief physicians of the nephrology, one chief nurse, and one supervisor nurse) evaluated the rationality of the sorted pool, gave reasons for 
adding or removing items, and prepared the initial lists, including the breakdown and checklist [10-13].

2.2. Preparation of Consultation Questionnaire. The consultation questionnaire was prepared according to the first draft of the revised breakdown and checklist (three parts): (1) letter to experts, in which the research objective, content, and significance were briefly introduced; (2) CRRT breakdown and checklist evaluation form, which was used to solicit expert opinions and suggestions on the setting and importance of the breakdown and checklist; (3) expert situation questionnaire, which was used to collect experts' general information, judgment basis, and familiarity with the research content.

2.3. Selection of Experts. The number of consultant experts should be determined based on the amount of research. It was reported [14] that the number of experts was generally set as $15-30$ to ensure the reliability of the inquiry results. Inclusion criteria of consultant experts in this study: (1) the clinicians and nurses in grade A class three hospitals, with over 10 years of experience in the field of renal replacement therapy; (2) with the bachelor degree or above, intermediate title or above; (3) with sufficient understanding of the study and can actively complete the expert consultation; and (4) with a willingness to participate in this study, were included. After screening, 18 experts from 5 provinces and municipalities were selected.

2.4. Expert Consultation. The consultation questionnaire was prepared according to the initial breakdown and checklist and sent to 12 experts by e-mail or field distribution from January to May 2018 for two rounds of an expert consultation. The questionnaires of the first round were collected and analyzed based on the summarized expert opinions and suggestions. Then, the contents were adjusted and distributed for the second round of consultation to make the breakdown and checklist more scientific, reasonable, and consistent.

2.5. Statistical Methods. Excel 2016 and SPSS 19.0 were used for data analysis and calculation of expert positivity coefficient, authority, arithmetic mean of various indicators, coefficient of variation, and coordination coefficient of opinions. The coordination of opinions was expressed by the Kendall coordination coefficient. $P<0.05$ was considered statistically significant. The indicators with the average score of importance and reliability $>3$ points, coefficient of variation $<25 \%$, and the full-score rate $>20 \%$ were retained and then modified and selected through panel discussion based on expert opinions and comprehensive consideration of all scientific indicators.

\section{Results}

3.1. Basic Data of Experts. Basic data of the selected 18 experts are shown in Table 1.
TABLE 1: Basic data of experts.

\begin{tabular}{|c|c|c|}
\hline General condition & Number & Proportion (\%) \\
\hline \multicolumn{3}{|l|}{ Age } \\
\hline $30-40$ & 3 & 16.7 \\
\hline $41-50$ & 9 & 50.0 \\
\hline$\geq 51$ & 6 & 33.3 \\
\hline \multicolumn{3}{|l|}{ Education background } \\
\hline Bachelor & 10 & 55.6 \\
\hline Master & 5 & 27.8 \\
\hline Ph.D. & 3 & 16.7 \\
\hline \multicolumn{3}{|l|}{ Title } \\
\hline Intermediate & 3 & 16.7 \\
\hline Subsenior & 9 & 50.0 \\
\hline Senior & 6 & 33.3 \\
\hline \multicolumn{3}{|l|}{ Years of working } \\
\hline $10-20$ & 2 & 11.1 \\
\hline $21-30$ & 12 & 66.7 \\
\hline$\geq 31$ & 4 & 22.2 \\
\hline \multicolumn{3}{|l|}{ Fields } \\
\hline Medicine & 6 & 33.3 \\
\hline Clinical care & 9 & 50.0 \\
\hline Administration & 3 & 16.7 \\
\hline
\end{tabular}

3.2. Expert Positivity Coefficient. The response rate of consultation questionnaire was used to calculate the expert positivity coefficient. As reported previously [15], the experts were considered highly positive when the expert positivity coefficient was higher than 70\%. 18 questionnaires were released for either round of expert consultation, and 18 and 16 were collected in the first and second rounds, with the response rate of $100 \%$ and $88.9 \%$, respectively, indicating high positivity of experts.

3.3. Expert's Authority. The expert's authority coefficient (Cr) was calculated based on the reason of judgment $(\mathrm{Ca})$ and degree of familiarity (Cs). Generally, it is believed that the authority coefficient not lower than 0.7 can be acceptable [16-18]. The expert's authority coefficient in the first round of consultation was $0.85(\mathrm{Ca}=0.89, \mathrm{Cs}=0.82)$, while $\mathrm{Ca}$ in the second round of consultation was 0.91 (Cs $=0.85$, $\mathrm{Cr}=0.88)$. The authority coefficients in both rounds were $>0.7$, indicating the high authority of the experts.

3.4. Coordination Degree of Opinions. The coefficient of variation and Kendall coordination coefficient were used to test the coordination of experts. The coefficients of variation were $0.03-0.36$ and $0.00-0.23$ in the first and second rounds of expert consultation, respectively, while the Kendall coordination coefficients were 0.296 and 0.303 , respectively, showing statistical significance $(P<0.05)$.

3.5. Consultation Results. The items were classified as very important (5 points), important (4 points), general (3 points), unimportant ( 2 points), and very unimportant (1 point). The experts were asked to score according to the degree of importance and gave the corresponding opinions in the columns of "suggestions on revision" and "items 
suggested to be added." The indicators with the mean score $>3$ points, coefficient of variation $<25 \%$, and full-score rate $>20 \%$ were retained, then deleted, and modified based on expert opinions.

In the first round of consultation, the primary indicators had the mean value of importance of 3.28-5.00 points, the coefficient of variation of $0.082-0.181$, and full-score rate of $10 \%-100 \%$, which were $4.02-5.00,0.000-0.284$, and $30 \%-$ $100 \%$ points, respectively, as for the secondary indicators. According to the screening conditions and expert opinions, the primary indicator "evaluation of hemofiltration tube" was merged into the primary indicator "preparation prior to operation."

According to the screening conditions, and in accordance with the experts' opinions and panel discussion, the primary indicator "evaluation of hemofiltration tube" was merged into "preparation prior to operation." The item "following the doctor's advice" under the secondary indicator "termination" was removed, and the secondary indicator "doctor's advice after termination" was added. The secondary indicators "date" and "wearing gloves" were removed. Moreover, "final treatment" and "evaluating patients' tolerance, and whether sedation or restraint is required" were added. As suggested by the experts, the warning signs "Caution: Use with caution in the case of liver dysfunction!" and "Note: Total calcium/free calcium $>2.5 \longrightarrow$ citrate accumulation" was added.

In the second round of consultation, the average value of importance of the primary indicators was 4.12-5.00, the coefficient of variation was $0.000-0.208$, and the full-score rate was $33.63 \%-100 \%$, which were $3.85-5.00$, $0.000-0.227$, and $30 \%-100 \%$, respectively, for secondary indicators. As suggested by the experts, the warnings were bolded in red. The item "evaluate the bleeding and coagulation of the patients" was changed to "check whether there are bleeding spots on the skin and mucosa and evaluate the bleeding and coagulation of the patients." Finally, the breakdown and checklist were prepared, which involved 16 primary indicators and 56 secondary indicators, respectively, whose consultation results are shown in Table 2.

\section{Discussion}

4.1. Reliability of Consultation Results. We performed two rounds of expert consultation based on document retrieval, clinical needs, and brainstorming of the CRRT team to ensure the scientificity and practicability of the breakdown and checklist. All the selected experts were familiar with the knowledge of CRRT and can provide clinical opinions combining theoretical and practical experience. The response rate of either round of consultation was $100 \%$, and the suggestions on modification were given, indicating that the experts highly supported this study. In the first round of consultation, the expert's authority coefficients were 0.85 and 0.88 in the first round, both of which were larger than 0.7 , indicating the high authority. After two rounds of consultation, the Kendall coordination coefficient of the secondary indicators was $0.303(P<0.05)$, indicating that the experts had high consistency on the contents of the breakdown and checklist, with only small divergences. Therefore, the consultation results of this study had a certain degree of reliability [16].

4.2. Scientificity of Consultation Results. In this study, the breakdown (involving 11 items of patient information, evaluation prior to operation, treatment mode, pipeline preflushing, anticoagulation method, replacement fluid, plasma exchange, blood flow rate, fluid balance, test indicators, and others) and checklist (involving 5 items of preparation prior to operation, preparation of pipeline, operation process, treatment process, and termination of operation) were prepared according to the mature domestic practice [6,7], studies of domestic scholars [8], and the related documents [9]. Given the multiple CRRT treatment parameters and modes, there would be errors in communication between doctors and nurses, doctors shifting, and operation preparation [3]. The checklist can be used to check patient information, examination prior to operation, treatment mode, pipeline preflushing, anticoagulation method, replacement fluid, plasma exchange, blood flow rate, fluid balance, and detection indicators, which the doctors and nurses should confirm to reduce the incidence of information transmission errors to "zero." The complicated CRRT treatment procedures, as well as their unskilled and irregular operations, can delay the treatment. The breakdown can be used to guide the whole operation process and enable the nurses of different levels, especially junior nurses, to operate in accordance with the standard and norms, and gradually complete the preparation prior to operation, pipeline preparation, operation, treatment, and termination to ensure that the nurses can efficiently complete the preparation prior to operation, thus avoiding omissions due to the complicated process and numerous steps.

\subsection{Significance of the Preparation of Breakdown and Checklist} for Continuous Renal Replacement Therapy (CRRT). CRRT, with professional theory and skills and high operational risks, has proposed higher requirements for the overall quality of nurses; however, in the application of CRRT technology, nursing is the key to successful treatment [19]. Firstly, the breakdown and checklist can realize the homogeneous management of the whole process from the doctor's advice to the end of treatment, examine and monitor the nurse operation procedures, and guide the junior nurses. The incidence of adverse events has been reduced from $9.1 \%$ to $1.4 \%\left(X^{2}=4.955\right.$, $P=0.026)$. Secondly, the checklist can improve the work efficiency, and the breakdown can make the doctor's advice clearer, thus effectively avoiding time delays due to doctor's advice, while the checklist can ensure the preparation of items at one time and the orderly advancement of the treatment process, thus avoiding the waste of time due to omissions in the complicated process. In terms of handover, the breakdown and checklist should be used to show the entire process to the 
TABLE 2: Results of the second round of consultation.

\begin{tabular}{|c|c|c|c|c|}
\hline & Indicators & $\begin{array}{l}\text { Value of } \\
\text { importance }\end{array}$ & $\begin{array}{l}\text { Coefficient of } \\
\text { variation }\end{array}$ & $\begin{array}{l}\text { Full-score } \\
\text { rate }(\%)\end{array}$ \\
\hline \multirow[t]{3}{*}{ Patient information } & & $5.00 \pm 0.00$ & 0.000 & 100 \\
\hline & Basic information & $5.00 \pm 0.00$ & 0.000 & 100 \\
\hline & Diagnosis & $5.00 \pm 0.00$ & 0.000 & 100 \\
\hline \multirow[t]{3}{*}{$\begin{array}{l}\text { Evaluation prior to } \\
\text { operation }\end{array}$} & & $4.33 \pm 0.62$ & 0.142 & 66.67 \\
\hline & CBP blood pathway & $4.73 \pm 0.59$ & 0.125 & 80.00 \\
\hline & Coagulation indicators prior to operation & $4.93 \pm 0.26$ & 0.052 & 87.77 \\
\hline \multirow[t]{3}{*}{ Treatment mode } & & $4.87 \pm 0.35$ & 0.072 & 80.00 \\
\hline & Mode selection & $4.67 \pm 0.49$ & 0.105 & 66.67 \\
\hline & Filter selection & $4.60 \pm 0.63$ & 0.137 & 66.67 \\
\hline \multirow[t]{3}{*}{ Pipeline preflushing } & & $4.47 \pm 0.64$ & 0.143 & 53.54 \\
\hline & Selection of preflush & $4.40 \pm 0.83$ & 0.188 & 60.00 \\
\hline & Preparation of preflush & $4.53 \pm 0.74$ & 0.164 & 66.67 \\
\hline \multirow[t]{3}{*}{$\begin{array}{l}\text { Anticoagulation } \\
\text { method }\end{array}$} & & $4.47 \pm 0.74$ & 0.166 & 60.00 \\
\hline & Anticoagulation with heparin & $4.80 \pm 0.41$ & 0.086 & 80.00 \\
\hline & Anticoagulation with $4 \%$ citric acid & $4.87 \pm 0.35$ & 0.072 & 86.67 \\
\hline \multirow[t]{4}{*}{ Replacement fluid } & & $4.27 \pm 0.59$ & 0.139 & 33.68 \\
\hline & Rate of front replacement fluid & $4.87 \pm 0.35$ & 0.072 & 60.00 \\
\hline & Rate of rear replacement fluid & $4.80 \pm 0.41$ & 0.086 & 80.00 \\
\hline & Rate of dialysate & $4.00 \pm 0.92$ & 0.231 & 40.00 \\
\hline \multirow[t]{2}{*}{ Plasma exchange } & & $4.40 \pm 0.74$ & 0.167 & 40.00 \\
\hline & Plasma separation rate & $4.87 \pm 0.35$ & 0.072 & 86.67 \\
\hline \multirow[t]{3}{*}{ Blood flow rate } & & $4.53 \pm 0.64$ & 0.141 & 60.00 \\
\hline & Initial blood flow rate & $4.33 \pm 0.72$ & 0.167 & 40.00 \\
\hline & Target blood flow rate & $4.27 \pm 0.80$ & 0.187 & 40.00 \\
\hline \multirow[t]{3}{*}{ Fluid balance } & & $4.33 \pm 0.90$ & 0.208 & 60.00 \\
\hline & The set ultrafiltration volume & $4.87 \pm 0.35$ & 0.072 & 86.67 \\
\hline & Target dehydration volume & $5.00 \pm 0.00$ & 0.000 & 100 \\
\hline \multirow[t]{3}{*}{ Detection indicators } & & $4.60 \pm 0.51$ & 0.110 & 60.00 \\
\hline & APTT-INR & $4.13 \pm 0.83$ & 0.202 & 40.00 \\
\hline & Arterial blood gas analysis & $4.20 \pm 0.68$ & 0.161 & 40.00 \\
\hline \multirow[t]{5}{*}{ Others } & & $4.93 \pm 0.26$ & 0.052 & 90.00 \\
\hline & $5 \%$ sodium bicarbonate & $4.73 \pm 0.46$ & 0.097 & 86.67 \\
\hline & $10 \%$ potassium chloride & $4.87 \pm 0.35$ & 0.072 & 90.00 \\
\hline & $5 \% \mathrm{CaCl}_{2}$ & $4.87 \pm 0.35$ & 0.072 & 90.00 \\
\hline & $10 \%$ sodium chloride & $4.67 \pm 0.62$ & 0.132 & 86.67 \\
\hline \multirow[t]{7}{*}{$\begin{array}{l}\text { Preparation prior to } \\
\text { operation }\end{array}$} & & $4.20 \pm 0.41$ & 0.099 & 40.00 \\
\hline & Checking of doctor's advice & $5.00 \pm 0.00$ & 0.000 & 100 \\
\hline & Patient preparation & $4.67 \pm 0.49$ & 0.105 & 66.67 \\
\hline & Preparation of materials & $4.60 \pm 0.63$ & 0.137 & 66.67 \\
\hline & Preparation of drugs & $4.80 \pm 0.41$ & 0.086 & 80.00 \\
\hline & Other preparations & $4.47 \pm 0.74$ & 0.166 & 60.00 \\
\hline & Evaluation of hemofiltration tube & $4.80 \pm 0.41$ & 0.086 & 80.00 \\
\hline \multirow[t]{7}{*}{ Pipeline preparation } & & $4.73 \pm 0.59$ & 0.125 & 80.00 \\
\hline & Checking tight type of the AVF tube & $4.93 \pm 0.26$ & 0.052 & 90.0 \\
\hline & Installing the pipeline according to the showed order & $4.27 \pm 0.96$ & 0.227 & 30.00 \\
\hline & Checking the four pressure monitoring sensors and all clamps & $4.60 \pm 0.51$ & 0.110 & 60.00 \\
\hline & Setting the preflushing volume and the related parameters & $5.00 \pm 0.00$ & 0.000 & 100 \\
\hline & $\begin{array}{c}\text { Adjusting the fluid level of the arteriovenous pot and removing } \\
\text { the air bubbles from the filter }\end{array}$ & $4.47 \pm 0.64$ & 0.143 & 60.00 \\
\hline & $\begin{array}{l}\text { In the case of preflushing outside the membrane, check the } \\
\text { direction of the filter, and reverse it if necessary }\end{array}$ & $4.84 \pm 0.35$ & 0.072 & 86.67 \\
\hline \multirow[t]{3}{*}{ Operation process } & & $4.48 \pm 0.57$ & 0.133 & 86.67 \\
\hline & $\begin{array}{c}\text { Checking the quality of preflushing, and making sure that it has } \\
\text { been completed }\end{array}$ & $4.41 \pm 0.38$ & 0.090 & 60.00 \\
\hline & Checking the smoothness of the hemofiltration tube & $4.64 \pm 0.52$ & 0.113 & 90.00 \\
\hline
\end{tabular}


TABLE 2: Continued.

\begin{tabular}{|c|c|c|c|c|}
\hline & Indicators & $\begin{array}{l}\text { Value of } \\
\text { importance }\end{array}$ & $\begin{array}{c}\text { Coefficient of } \\
\text { variation }\end{array}$ & $\begin{array}{l}\text { Full-score } \\
\text { rate }(\%)\end{array}$ \\
\hline \multirow{10}{*}{ Treatment process } & $\begin{array}{l}\text { Pressing the button "Stop" before introducing the blood to make } \\
\text { sure that the pump is stopped and the patient connection } \\
\text { interface is displayed }\end{array}$ & $4.04 \pm 0.74$ & 0.184 & 40.00 \\
\hline & $\begin{array}{l}\text { Observing the hemodynamic changes before and during the } \\
\text { connection }\end{array}$ & $4.14 \pm 0.58$ & 0.147 & 60.00 \\
\hline & $\begin{array}{c}\text { Adjusting the replacement dialysis volume, blood flow rate, } \\
\text { ultrafiltration volume, and other parameters }\end{array}$ & $5.00 \pm 0.00$ & 0.000 & 100 \\
\hline & Properly fixing the hemofiltration tube & $4.83 \pm 0.31$ & 0.066 & 60.00 \\
\hline & & $4.12 \pm 0.35$ & 0.082 & 86.67 \\
\hline & $\begin{array}{l}\text { Observing the changes in heart rate, blood pressure, and } \\
\text { hemodynamic stability of each patient }\end{array}$ & $4.23 \pm 0.27$ & 0.064 & 90.00 \\
\hline & $\begin{array}{c}\text { Checking whether there are bleeding spots on the skin and } \\
\text { mucosa and evaluating the bleeding and coagulation of the } \\
\text { patients }\end{array}$ & $4.37 \pm 0.32$ & 0.072 & 90.00 \\
\hline & $\begin{array}{c}\text { Paying attention to the evaluation of the dehydration amount, } \\
\text { urine volume, and water intake }\end{array}$ & $4.21 \pm 0.51$ & 0.124 & 80.00 \\
\hline & Paying attention to the changes in various assay values & $4.14 \pm 0.35$ & 0.086 & 86.67 \\
\hline & $\begin{array}{c}\text { Evaluating patients' tolerance and whether sedation or restraint is } \\
\text { required }\end{array}$ & $4.45 \pm 0.32$ & 0.072 & 60.00 \\
\hline \multirow{10}{*}{ Termination } & $\begin{array}{c}\text { Dealing with various alarms in time and paying attention to the } \\
\text { changes of various parameters }\end{array}$ & $5.00 \pm 0.00$ & 0.000 & 100 \\
\hline & $\begin{array}{c}\text { Paying attention to the conditions of the skin to prevent pressure } \\
\text { sores }\end{array}$ & $4.12 \pm 0.43$ & 0.100 & 60.00 \\
\hline & $\begin{array}{l}\text { Paying attention to the conditions of edema of the lower } \\
\text { extremity to prevent thrombus of lower extremity veins }\end{array}$ & $4.30 \pm 0.30$ & 0.072 & 86.67 \\
\hline & $\begin{array}{c}\text { Assisting patients in proper bed movement to prevent thrombus } \\
\text { of lower extremity veins }\end{array}$ & $3.85 \pm 0.71$ & 0.180 & 40.00 \\
\hline & & $4.55 \pm 0.54$ & 0.126 & 60.00 \\
\hline & Indications after termination & $4.81 \pm 0.24$ & 0.050 & 80.00 \\
\hline & Doctor's advice after termination & $5.00 \pm 0.00$ & 0.00 & 100 \\
\hline & $\begin{array}{c}\text { Observation of the changes in heart rate and blood pressure of the } \\
\text { patient }\end{array}$ & $4.84 \pm 0.11$ & 0.020 & 90.00 \\
\hline & $\begin{array}{c}\text { Prompt reminding of adjusting the amount of the pumped insulin } \\
\text { and antibiotics }\end{array}$ & $4.31 \pm 0.32$ & 0.126 & 40.00 \\
\hline & Final treatment & $4.51 \pm 0.53$ & 0.070 & 60.00 \\
\hline
\end{tabular}

successor to improve the efficiency and save handover time. Finally, the breakdown and checklist can improve the satisfaction of doctors and nurses, further clarify their responsibilities, and improve the effectiveness of communication between doctors and nurses [2]. Meanwhile, they can also help doctors and nurses to comprehensively understand the conditions of patients and the setting and adjustment of parameters during treatment. Moreover, it can improve the tacit understanding and truly reflect the treatment process of the integration of healthcare. Since their application, the satisfaction of medical care has been increased from $87 \%$ to $97.8 \%\left(X^{2}=7.263, P=0.026\right)$.

\section{Conclusion}

This study constructs a CRRT nursing management plan; that is, a table, including 16 main indicators and $56 \mathrm{sec}$ ondary indicators, and the indicators have good internal quality. Through clinical exploration, it has provided scientific basis for the nursing management of CRRT patients and has improved the job satisfaction of medical staff.

\section{Data Availability}

The datasets used and/or analyzed during the current study are available from the corresponding author on reasonable request.

\section{Conflicts of Interest}

The authors declare that they have no conflicts of interest.

\section{References}

[1] X. H. Qiu and H. B. Qiu, "Progress in the application of CRRT in patients with serious infection," Chinese Journal of Emergency Medicine, vol. 20, no. 7, pp. 774-776, 2011.

[2] D. Y. Li, J. J. Wang, X. Li et al., "Design and application of continuous renal replacement therapy checklist for ICU patients," Chinese Nursing Management, vol. 19, no. 8, pp. 1180-1184, 2019.

[3] L. L. Kong, E. H. Chen, and Y. L. Qiu, "Design and application of nursing checklist for continuous renal replacement therapy in ICU patients," Chinese Journal of Nursing, vol. 52, no. 5, pp. 558-560, 2017. 
[4] T. Liyanage, T. Ninomiya, V. Jha et al., "Worldwide access to treatment for end-stage kidney disease: a systematic review," The Lancet, vol. 385, no. 9981, pp. 1975-1982, 2015.

[5] J. M. Spector, P. Agrawal, B. Kodkany et al., "Improving quality of care for maternal and newborn health: prospective pilot study of the WHO safe childbirth checklist program," PLoS One, vol. 7, no. 5, Article ID e35151, 2012.

[6] Ministry of Health, Standard Operating Proceduse of Blood Purification Center, Ministry of Health, Colombo, Sri Lanka, 2010.

[7] Y. Zou, H. Wu, X. Guo et al., "MK-FSVM-SVDD: a multiple kernel-based fuzzy SVM model for predicting DNA-binding proteins via support vector data description," Current Bioinformatics, vol. 16, no. 2, pp. 274-283, 2021.

[8] W. Tang, S. Wan, Z. Yang, A. E. Teschendorff, Q. Zou, and C. Sahinalp, "Tumor origin detection with tissue-specific miRNA and DNA methylation markers," Bioinformatics, vol. 34, no. 3, pp. 398-406, 2018.

[9] Y. Wang, C. Ye, and Q. Jin, "Vascular pathway working group of Chinese hospital association blood purification center branch. Chinese blood dialysis system expert consensus (the first edition)," Chinese Journal of Blood Purification, vol. 13, no. 8, pp. 549-558, 2014.

[10] H. Zhu and H. Wang, "Effect of certain quinones on adenosine triphosphate level in human bladder cancer cells," Indian Journal of Pharmaceutical Sciences, vol. 82, pp. 1-6, 2020.

[11] X. Wang and Q. Yuan, "Evaluation of cognitive behaviour combined with biofeedback therapy based on the fusion of normed space and banach space on the emotional state of patients with coronary artery bypass grafting," Indian Journal of Pharmaceutical Sciences, vol. 82, pp. 7-13, 2020.

[12] Y. Liu, A. Li, G. Xie, G. Liu, and X. Hei, "Computational methods and online resources for identification of piRNARelated molecules," Interdisciplinary Sciences: Computational Life Sciences, vol. 13, no. 2, pp. 176-191, 2021.

[13] L. Chen and X. Xu, "Effect evaluation of the long-term care insurance (LTCI) system on the health care of the elderly: a review," Journal of Multidisciplinary Healthcare, vol. 13, pp. 863-875, 2020.

[14] L. N. Chen and L. H. Zhang, "Investigation on construction of hospital innovation capacity evaluation index system," Chinese Health Quality Management, vol. 24, no. 2, pp. 117-120, 2017.

[15] C. Wang and T. Sun, "Construction evaluation index system for scientific and technological innovation ability of research hospitals," Chinese Health Quality Management, vol. 26, no. 3, pp. 130-133, 2019.

[16] X. Feng, J. Tian, B. Q. Wang et al., "Formulation of a nurse-led follow-up checklist for patients with laryngeal neoplasms," Chinese Journal of Nursing, vol. 53, no. 8, pp. 956-961, 2018.

[17] L. Wing, G. Ding, J. Xue, and Y.-W. Zhang, "PKN2 regulates the survival of pc12 cells by activating the AKT/mTOR pathway," Indian Journal of Pharmaceutical Sciences, vol. 82, p. 8, 2020.

[18] Z. Yun, Z. Hong, and Z. Dengchuan, "Risk factor analysis of pan-drug resistant acinetobacter baumannii-induced ventilator-associated pneumonia in ICU," Indian Journal of Pharmaceutical Sciences, vol. 82, pp. 8-11, 2020.

[19] S. D. Fei, J. F. Jin, H. Y. Wang, F. Ceng, Y. H. Xu, and J. F. CHen, "The related factors of unplanned interruption during continuous renal replacement therapy," Chinese Journal of Nursing, vol. 50, no. 1, pp. 57-61, 2015. 